\title{
Application of Coal Ash to Postmine Land for Prevention of Soil Erosion in Coal Mine in Indonesia: Utilization of Fly Ash and Bottom Ash
}

\author{
Shinji Matsumoto, ${ }^{1}$ Shunta Ogata, ${ }^{1}$ Hideki Shimada, ${ }^{1}$ Takashi Sasaoka, ${ }^{1}$ \\ Ginting J. Kusuma, ${ }^{2}$ and Rudy S. Gautama ${ }^{2}$ \\ ${ }^{1}$ Department of Earth Resources Engineering, Kyushu University, 744 Motooka, Nishi-ku, Fukuoka 8190395, Japan \\ ${ }^{2}$ Department of Mining Engineering, Institute of Technology Bandung, Jalan Ganesha No. 10, Bandung, Jawa Barat 40132, Indonesia
}

Correspondence should be addressed to Shinji Matsumoto; shinji12@kyudai.jp

Received 21 April 2016; Accepted 17 July 2016

Academic Editor: Guocheng Lv

Copyright @ 2016 Shinji Matsumoto et al. This is an open access article distributed under the Creative Commons Attribution License, which permits unrestricted use, distribution, and reproduction in any medium, provided the original work is properly cited.

\begin{abstract}
The increase in the number of coal-fired power plants with the increase in coal production and its consumption has caused the problem of the treatment of a large amount of coal ash in Indonesia. In the past studies, coal ash was applied to postmine land with the aim of improving soil conditions for plant growth; however, heavy rain in the tropical climate may cause soil erosion with the change in soil conditions. This study presents the effects of application of coal ash to postmine land on soil erosion by performing the artificial rainfall test as well as physical testing. The results indicate that the risk of soil erosion can be reduced significantly by applying the coal ash which consists of more than $85 \%$ of sand to topsoil in the postmine land at the mixing ratio of over $30 \%$. Additionally, they reveal that not only fine fractions but also microporous structures in coal ash enhance water retention capacity by retaining water in the structure, leading to the prevention of soil erosion. Thus, the risk of soil erosion can be reduced by applying coal ash to topsoil in consideration of soil composition and microporous structure of coal ash.
\end{abstract}

\section{Introduction}

Indonesia is one of the largest coal exporters in the world, and the amount of coal production and the export has grown at an annual average rate of more than $10 \%$ since 2000 [1]. The increase in domestic demand for coal with economic growth has promoted the energy policy such as the conversion to coal-fired power generation and the construction of new coal-fired plant in Indonesia [2]. This change created the problem of the disposal of a large amount of coal ash [3]. Although coal ash such as fly ash and bottom ash are, generally, disposed of to landfill as industrial waste, the efficient use of them is required due to landfill shortage. $80 \%$ of coal ash has ever been reutilized as cement raw materials in Indonesia; however, alternative proposal for effective use of them is needed in consideration of the increase in the amount of coal ash in the future. In the past studies, coal ash was utilized for improvement of soil conditions in revegetation area [4-7]. Though coal ash was also used for reclamation in mining areas in some cases [8-11], a high annual precipitation and a squall in the tropical climate in Indonesia may cause soil erosion with the change in soil conditions in the area. Evaluation of soil erosion in postmine land to which coal ash is applied is important to verify the applicability of coal ash to postmine land as well as the effects on plant growth. However, soil erosion in postmine land to which coal ash was applied in Indonesia was evaluated in a few studies.

Coal ash is produced with combustion gas by variation of ash composed of $\mathrm{SiO}_{2}$ and $\mathrm{Al}_{2} \mathrm{O}_{3}$ after carbon and hydrogen burn in coal-fired power plant. The physical and chemical properties of coal ash are dependent on combustion process and power plant design [12]. Thus, the physical and chemical properties affect the applicability of coal ash in postmine land.

In the tropical climate where annual rainfall exceeds $2,500 \mathrm{~mm}$, heavy rain and/or squall is a major cause of soil erosion [13]. Figure 1 shows the mechanism of soil erosion. 


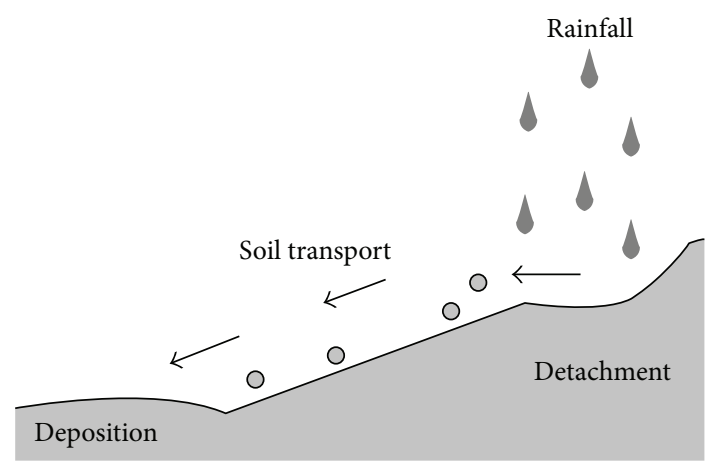

Figure 1: Mechanism of soil erosion.

Firstly, soil fractions retain water and are detached by the impact from collision of raindrop. Soil fractions detached from the ground are flown by surface stream water, resulting in the deposition of soil fractions. Soil erosion progresses through this process due to rainfall. The degree of soil erosion is dependent on intensity of rainfall, rain duration, and raindrop energy. Higher intensity of rainfall and that for long term facilitate the transfer of soil fraction [14]. The degree also depends on soil composition, soil permeability, and the Atterberg limits of soils. Soil composition affects permeability and the Atterberg limits of soils [15]. Since a high infiltration rate of water into the ground decreases the development of surface water flow, the soils which show high permeability such as sand and gravel are less likely to cause soil erosion than clay and silt which show low permeability $[16,17]$. Moreover, the Atterberg limits indicate the change in physical properties of soils with the change in water content and the resistance to deformation force, and it depends on soil composition. Thus, the Atterberg limits which are influenced by fine fraction in soils affect water retention capacity of soils as well as soil erosion $[17,18]$. These characteristics are considered one of the predictive indicators for soil erosion.

For the reasons, the objective of this research is to understand the effects of the application of coal ash to postmine land on soil erosion, aiming at efficient use of coal ash in postmine land in Indonesia. Soil erosion is to be evaluated by performing the artificial rainfall test as well as physical testing with the simulated topsoil mixed with coal ash in this study.

\section{Materials and Methods}

2.1. Materials. Fly ash and bottom ash were taken in A coalfired power plant in the K mine in Indonesia: FAl and BA1. Another type of fly ash was also sampled in B coal-fired power plant in Japan: FA2. The difference in the combustion process and the power plant design between the coal-fired power plants suggests the difference in the physical and chemical properties of the coal ash samples. For the purpose of understanding the chemical and physical properties of them, specific gravity measurement by using pycnometer, $\mathrm{X}$ Ray Fluorescent (XRF), X-Ray Diffraction (XRD), scanning electron microscope (SEM), and water retention test were
TABLE 1: Physical and chemical properties of the coal ash.

\begin{tabular}{lccc}
\hline Samples & FA1 & BA1 & FA2 \\
\hline Physical properties & & & \\
$\quad$ Specific gravity $\left(\mathrm{g} / \mathrm{cm}^{3}\right)$ & 2.10 & 1.96 & 2.07 \\
Chemical composition (mass\%) & & & \\
$\mathrm{SiO}_{2}$ & 30.93 & 44.56 & 67.39 \\
$\mathrm{Al}_{2} \mathrm{O}_{3}$ & 13.30 & 16.48 & 18.70 \\
$\mathrm{FeO}$ & 5.93 & 7.60 & 4.16 \\
$\mathrm{MgO}$ & 2.24 & 2.73 & 1.10 \\
$\mathrm{CaO}$ & 1.82 & 2.34 & 2.87 \\
$\mathrm{Na}$ & 0.16 & 0.46 & 0.67 \\
$\mathrm{~K}_{2} \mathrm{O}$ & 1.54 & 1.69 & 1.23 \\
$\mathrm{SO}_{3}$ & 1.21 & 7.22 & 0.22 \\
$\mathrm{H}_{2} \mathrm{O}$ & 41.02 & 22.32 & 1.97 \\
\hline
\end{tabular}

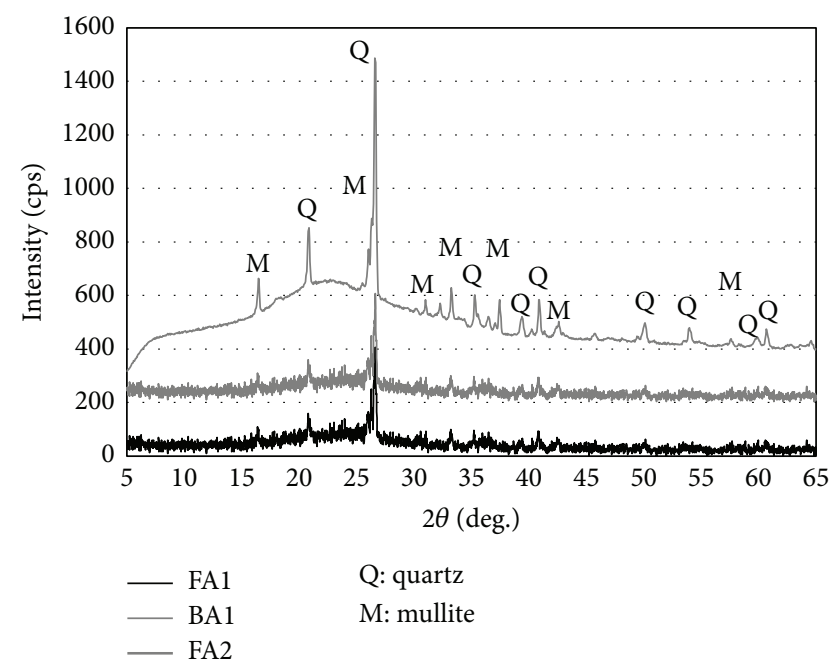

FIgURE 2: XRD patterns of the coal ash.

performed with the samples. The physical and chemical properties of the coal ash samples are summarized in Table 1. Figure 2 shows XRD patterns of them and Figure 3 shows SEM images. The results of water retention test are shown in Figure 4 .

2.2. Sample Preparation. Simulated topsoil was prepared by mixing the decomposed granite produced by the Gulin KitaKyu Co., Ltd., and the Kyushu Bentonite produced by the Shinagawa Yogyo Co., Ltd., after screening on the basis of soil conditions measured in postmine land in the mine as shown in Table 2. The simulated topsoil was replaced by the coal ash of FA1, BA1, and FA2 at the rates of $0 \%, 30 \%, 60 \%$, and $100 \%$ in order to evaluate the application of coal ash to topsoil in postmine land. They were named as topsoil ( $0 \%)$ without coal ash, FA1-30, FA1-60, FA1-100, BA1-30, BA1-60, BA1-100, FA2-30, FA2-60, and FA2-100, respectively. The samples were homogeneously mixed by the cone and quartering method. The grain size analysis, the standard test for the Atterberg limits, and the falling head permeability test were performed with the samples in order to understand the effects of 


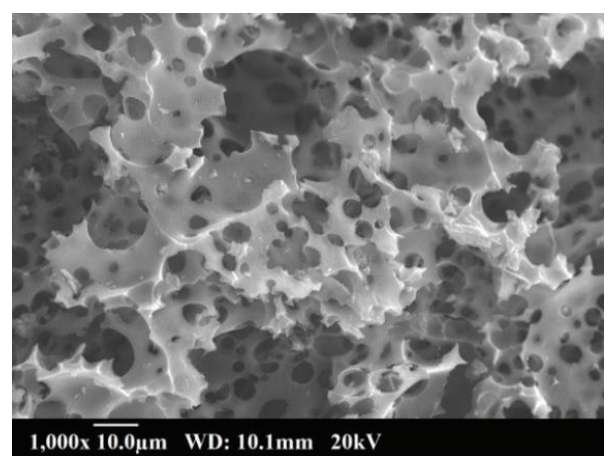

(a) FA1

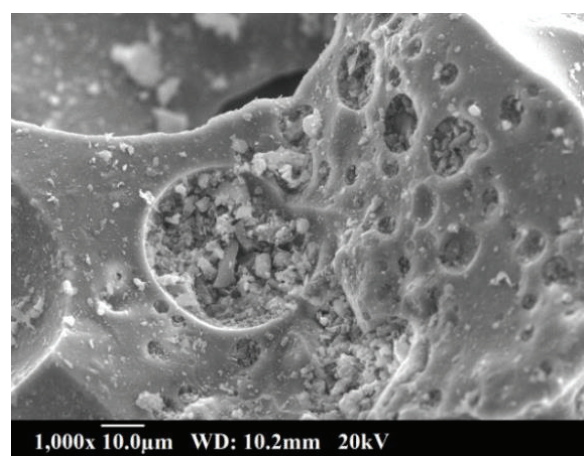

(b) BA1

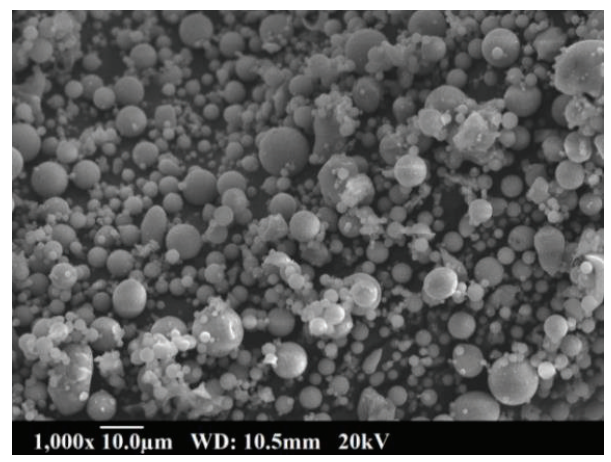

(c) FA2

FIGURE 3: SEM images of the coal ash.

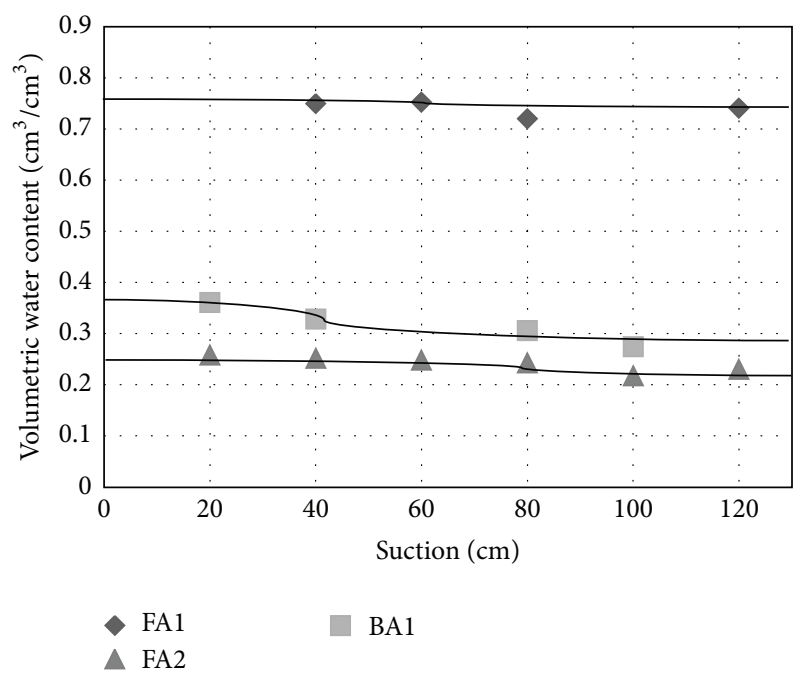

FIGURE 4: Water retention characteristics of the coal ash: curve approximation was drawn by the Van Genuchten model.

the application of coal ash on chemical and physical properties of soils.

\subsection{Experimental Methods}

2.3.1. XRD Analysis. FA1, BA, and FA2 were supplied to XRD analysis after drying at $80^{\circ} \mathrm{C}$ for 24 hours in an oven by using
TABLE 2: Soil texture classes of topsoil in the $\mathrm{K}$ mine and the simulated topsoil.

\begin{tabular}{lccc}
\hline Samples & Sand (\%) & Silt (\%) & Clay (\%) \\
\hline Topsoil in K mine & $2.7-48.9$ & $26.6-57.8$ & $24.4-39.6$ \\
Simulated topsoil & 36.7 & 26.7 & 36.6 \\
\hline
\end{tabular}

wide angle goniometer RINT 2100 XRD under the conditions: radiation $\mathrm{CuK} \alpha$, step scanning $0.050^{\circ}$, scan speed $2.000^{\circ} / \mathrm{min}$, and scan range $2.000-65.000^{\circ}$.

2.3.2. SEM Observation. The surface condition of FA1, BA, and FA2 was observed by using KEYENCE VE- 9800 . The AuPd coating was conducted prior to making SEM observations on the surface of the samples with the MSP-1S Magnetron Sputter. The specimens were vacuum-dried using a beam at $20 \mathrm{kV}$, followed by the beginning of SEM observation.

2.3.3. Physical Properties. Specific gravity of the samples was measured by using pycnometer based on the ASTM D85414 [19]. Particle size distribution of samples was analyzed based on the ASTM D422-63 [20]. In this test, the samples were categorized into sand, silt, and clay according to the classification. Atterberg limits test, which is to understand the change in mechanical behavior of soils with the change in water content, was also performed according to the ASTM 


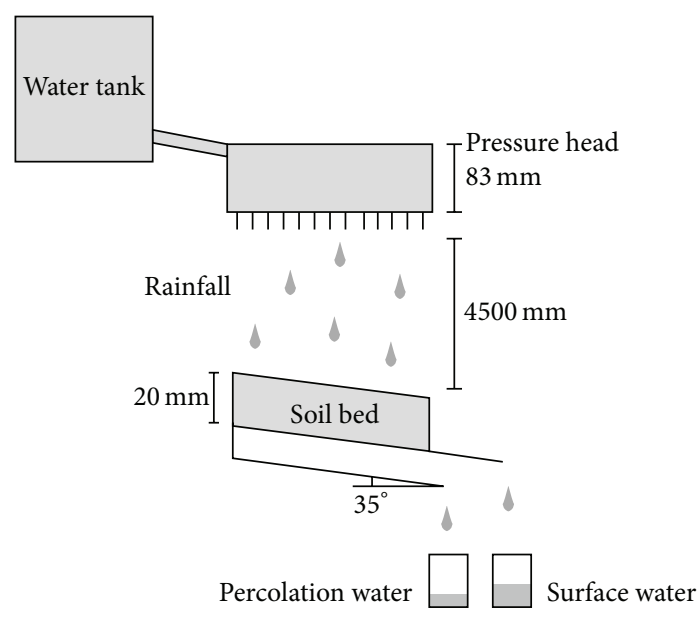

FIGURE 5: Schematic design of the artificial rainfall test.

D4318-05 [21]. Hydraulic conductivity of the samples was measured by conducting falling head permeability test based on the ASTM D5084-10 standard [22].

Additionally, the test for water retention capacity of the samples was conducted based on the standard of JGS 01512009 in order to measure the relationship between suction head and volumetric water content [23]. After the test, the web interface of the SWRC Fit was used to draw soil water retention curve by inputting the results and fitting by the Van Genuchten model [24].

2.3.4. Artificial Rainfall Test. The amount of annual soil erosion was measured by performing the artificial rainfall test in which artificial precipitation was supplied for an hour to the simulated topsoil mixed with coal ash. Figure 5 shows the schematic design of the equipment of the artificial rainfall test. After collecting surface stream water, they were dried at $100^{\circ} \mathrm{C}$ in an oven and the weight of the residue was measured, followed by the calculation of the amount of soil erosion per an hour. We substitute the amount of soil erosion per an hour $E$, the annual rainfall $R$, the section area $A$, the dry density of each sample $G$, and rain intensity $I$ into the equation to calculate the annual soil erosion $H$ as follows:

$$
H=\frac{(R \times E)}{(A \times G \times I)},
$$

where $H$ is the annual soil erosion (cm/year), $E$ is the soil erosion (g/hour), $G$ is the dry density $\left(\mathrm{g} / \mathrm{cm}^{3}\right), A$ is the section area $\left(\mathrm{cm}^{2}\right), R$ is the annual rainfall ( $\mathrm{mm} /$ year), and $I$ is the rain intensity ( $\mathrm{mm} /$ hour).

In this test, the rainfall intensity was set at 80 ( $\mathrm{mm} /$ hour) which was recorded in the postmine land in the mine when concentrated heavy rain occurred and based on the data in the past [25-27]. Moreover, water content was set at $15 \%$ which was measured in the postmine land. The slope angle was set at $35^{\circ}$ which is maximum slope angle at waste dump in the postmine land according to the standard in the mine. The annual rainfall was set at $3000(\mathrm{~mm} /$ year $)$ as the average value in Indonesia [28]. $240 \mathrm{~mm}$ by $155 \mathrm{~mm}$ of the case was filled with the simulated topsoil mixed with each type of coal ash by equalizing the filling rate in each case. The rainfall intensity was adjusted by changing hydraulic head. The surface stream water and the percolation water were collected separately and the volume was recorded during the test. The proportion of surface stream water and the percolation water to the total volume was calculated based on the results. The water content in the simulated topsoil was also measured by drying the soil samples in an oven at the end of the experiment. The rainfall test was conducted under the same conditions with each type of the samples. Besides, the risk of soil erosion was evaluated based on the results according to the risk assessment guideline of soil erosion in Indonesia as shown in Table $4[26,27]$.

\section{Results and Discussion}

3.1. Characterization of Topsoil Mixed with the Ash Samples. The physical and chemical properties of the coal ash samples are listed in Table 1 . The specific gravity of each type of the coal ash showed similar values: those of FA1, BA1, and FA2 were $2.10,1.96$, and $2.07\left(\mathrm{~g} / \mathrm{cm}^{3}\right)$, respectively. Since specific gravity of fly ash is, typically, between 2.1 and $3.1\left(\mathrm{~g} / \mathrm{cm}^{3}\right)$, they are typical fly ash samples [29]. Based on the chemical composition of the samples, $\mathrm{Si}$ and $\mathrm{Al}$ constituted more than half of BA1 and FA2. Additionally, the water content was higher in FA1 and BA1 than that in FA2, indicating that FA1 and BA1 contained unburnt materials. It would appear that the difference in the combustion temperature and/or the combustion efficiency between the coal-fired power plants caused the difference among the samples.

The XRD patterns of the coal ash samples in Figure 2 indicated that they mostly consisted of quartz and mullite, and there was not a large difference in XRD patterns among the samples. This result also suggested that the coal ash samples were typical coal ash due to the content of quartz and mullite in the past studies [30-32]. Meanwhile, the microstructure among the samples varied greatly as seen in the SEM images in Figure 3. FA1 had microporous structures of $1-10 \mu \mathrm{m}$ in diameter without fine fragments. Angular structure without microporous structures and fine fragments was observed in BA1, whereas the aggregation of $1-10 \mu \mathrm{m}$ diameters of spherical particles without microporous structure was found in FA2. Thus, the coal ash samples had a completely different microstructure while they consisted of the same minerals.

Figure 4 presents soil water retention characteristic (SWRC) of the coal ash samples. It can be seen that the water content was higher in FA1 than the others at each suction pressure and that of FA2 changed at lowest level. This implied that FA1 contained fine fractions more than in BA1 and FA2 by reason that water retention capacity in soils increases due to fine fraction $[17,18]$.

The soil composition of the simulated topsoil mixed with $0 \%, 30 \%, 60 \%$, and $100 \%$ of the coal ash samples is shown in Figure 6. Soil composition of the simulated topsoil mixed with $0 \%$ of coal ash was set at $36.7 \%$ of sand, $26.7 \%$ of silt, and $36.6 \%$ of clay based on the data in Table 2 . The result indicated that more than $85 \%$ of FAl and BAl consisted of 


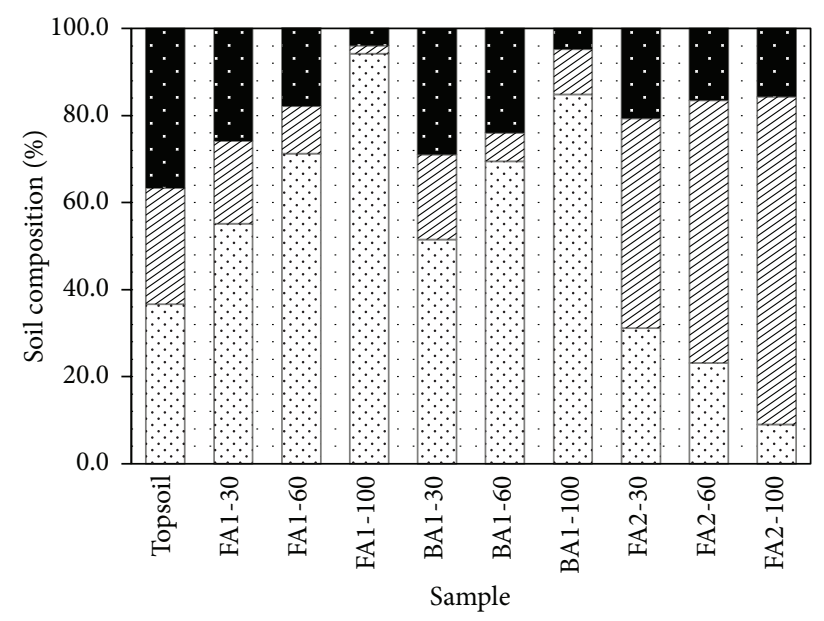

Clay
Sand
Silt

FIGURE 6: Soil composition of the simulated topsoil mixed with the coal ash at the mixing ratio of $0 \%, 30 \%, 60 \%$, and $100 \%$.

sand and more than $75 \%$ of FA2 consisted of silt. Therefore, the proportion of sand rose and that of silt dropped with the increase in the mixing ratio of FAl and BA. On the other hand, the percentage of sand and clay decreased and that of silt increased with the increase in the mixing ratio of FA2. The result was not consistent with the result of SWRC. The highest water retention capacity was obtained in FAl despite a high percentage of sand, and the lowest water retention capacity was recorded in FA2 despite a high percentage of silt considered as fine fractions. It would appear based on the SEM images in Figure 3 that FA1 had the high water retention capacity by retaining water in the microporous structure. Meanwhile, there were no voids which can retain water among the spherical particles in FA2, resulting in low water retention capacity in spite of a high content of silt. Thereby, microstructure of coal ash has to be taken into account in order to evaluate water retention capacity since high water retention capacity is obtained in the coal ash with microporous structures despite a low content of fine fractions.

Figure 7 shows the permeability of the samples and Table 3 presents the summary of the results of the Atterberg limits test. The physical properties were also changed by mixing the simulated topsoil with the coal ash samples. While the permeability of the simulated topsoil increased with the increase in the mixing ratio of FA1 and BA1 which consisted of more than $85 \%$ of sand, it decreased by mixing FA2 which consisted of more than $75 \%$ of silt. The change in permeability agreed with the soil composition of each sample in terms of the improvement of permeability by mixing sand $[17,18]$. In Table 3, liquid limit, plastic limit, and plasticity index were not measured after mixing the coal ash into the simulated topsoil. This was due to a significant decrease in adhesion caused by a high content of sand in FAl and BA1 and due to a significant increase in adhesion caused by a high content of silt in FA2.

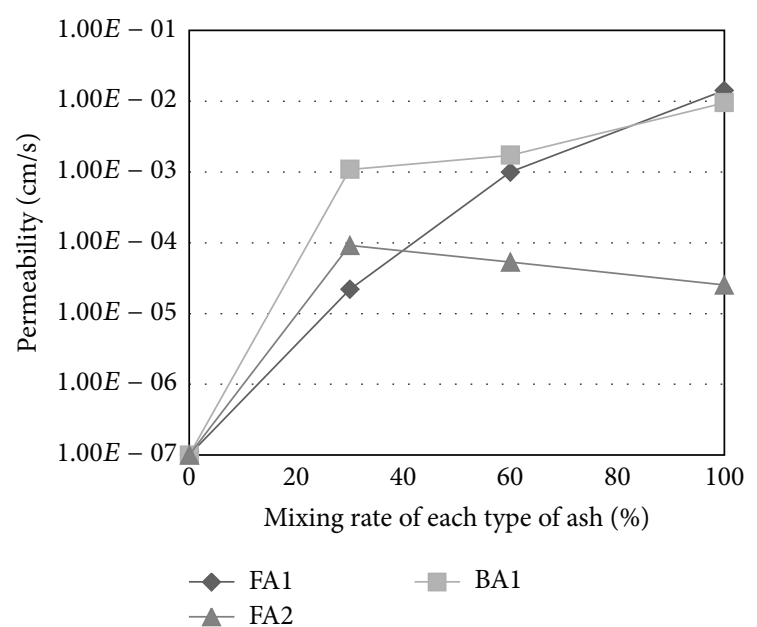

FIgURE 7: Permeability of the simulated topsoil mixed with the coal ash at the mixing ratio of $0 \%, 30 \%, 60 \%$, and $100 \%$.

TABLE 3: The Atterberg limits of the simulated topsoil mixed with the coal ash at the mixing ratio of $0 \%, 30 \%, 60 \%$, and $100 \%$.

\begin{tabular}{lccc}
\hline & $\begin{array}{c}\text { Liquid limit } \\
\left(W_{L}\right)\end{array}$ & $\begin{array}{c}\text { Plastic limit } \\
\left(W_{P}\right)\end{array}$ & $\begin{array}{c}\text { Plasticity } \\
\text { index }\left(I_{P}\right)\end{array}$ \\
\hline Topsoil (0\%) & 18.6 & 34.4 & 15.8 \\
FA1-30 & ND & ND & ND \\
FA1-60 & ND & ND & ND \\
FA1-100 & ND & ND & ND \\
BA1-30 & ND & ND & ND \\
BA1-60 & ND & ND & ND \\
BA1-100 & ND & ND & ND \\
FA2-30 & ND & 14.1 & ND \\
FA2-60 & ND & ND & ND \\
FA2-100 & ND & ND & ND \\
\hline
\end{tabular}

TABLE 4: Risk assessment of soil erosion in Indonesia.

\begin{tabular}{lc}
\hline Class & Surface soil loss (cm/year) \\
\hline Very high & $>4.8$ \\
High & $1.8-4.8$ \\
Moderate & $0.9-1.8$ \\
Low & $0.15-0.9$ \\
Very low & $<0.15$ \\
\hline
\end{tabular}

It was impossible to shape the simulated topsoil mixed with FA1 and BA1 owing to detachment of fractions and owing to liquefaction of them in FA2. It suggested that the observation of microstructure of coal ash was useful to evaluate water retention capacity in the case that the Atterberg limits could not be measured.

For the results, the application of FA1 to topsoil is, especially, expected to control soil erosion due to adhesion among fine fractions caused by high water retention capacity $[17,18]$. Furthermore, it is expected that surface stream water may easily occur by applying FA2 which shows low 


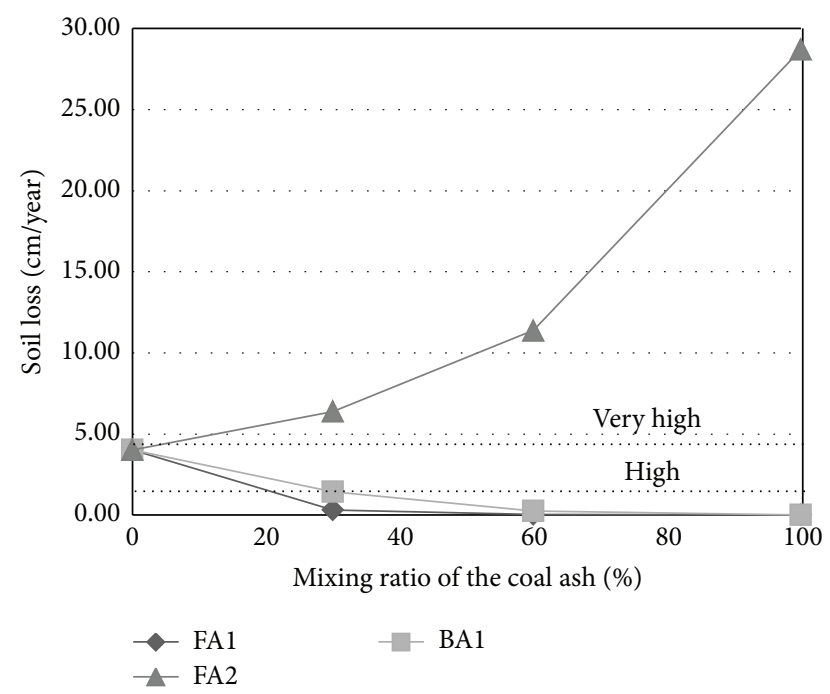

FIGURE 8: Soil loss of the simulated topsoil mixed with the coal ash at the mixing ratio of $0 \%, 30 \%, 60 \%$, and $100 \%$ in the artificial rainfall test: a range framed by dotted lines indicates high risk of soil erosion.

permeability contrary to FA1 due to a high content of silt, leading to soil erosion.

3.2. Soil Erosion in Artificial Rainfall Test. Figure 8 shows the amount of soil loss at the different mixing ratio of the coal ash into the simulated topsoil in the artificial rainfall test, and Figure 9 shows the change in water content in the samples during the test. The risk of soil erosion based on the standard in Indonesia is drawn with dashed lines in Figure 8 [26, 27]. The percentage of surface stream water and percolation water in the rainfall test is presented in Figure 10. From Figure 8, it was found that soil erosion was prevented significantly by applying FA1 and BA1 to the simulated topsoil. The risk of soil erosion was reduced from the category of "high" to that of "very low" in the standard by applying more than $30 \%$ of FA1 or BA1: the risk is considered very low when surface soil loss is less than 0.15 (cm/year). Soil loss was reduced by up to $4.00(\mathrm{~cm} /$ year) by applying FAl and BA1. On the other hand, the condition was classified into the category of "very high" by applying more than $30 \%$ of FA2 to the simulated topsoil. Soil loss increased by up to 24.68 ( $\mathrm{cm} /$ year) by mixing FA2 with the simulated topsoil. Moreover, these results agree with the discussion of the effects of the application of the coal ash on soil erosion on the basis of physical and chemical properties of the ash mentioned previously. High water content was obtained in Figure 9 in the sample mixed with FA1 which showed high water retention capacity, whereas similar change in water content was obtained in the sample mixed with BA1 and FA2 which showed similar water retention capacity.

Figure 10 demonstrates that the percentage of surface stream water decreased contrary to the increase in the ratio of percolation water by applying FAl and BAl with high permeability. When FA2 with low permeability was applied, there was an upward trend in the ratio of surface stream water.

Thus, the risk of soil erosion declined with the increase in the mixing ratio of FA1 and BA1 with high permeability

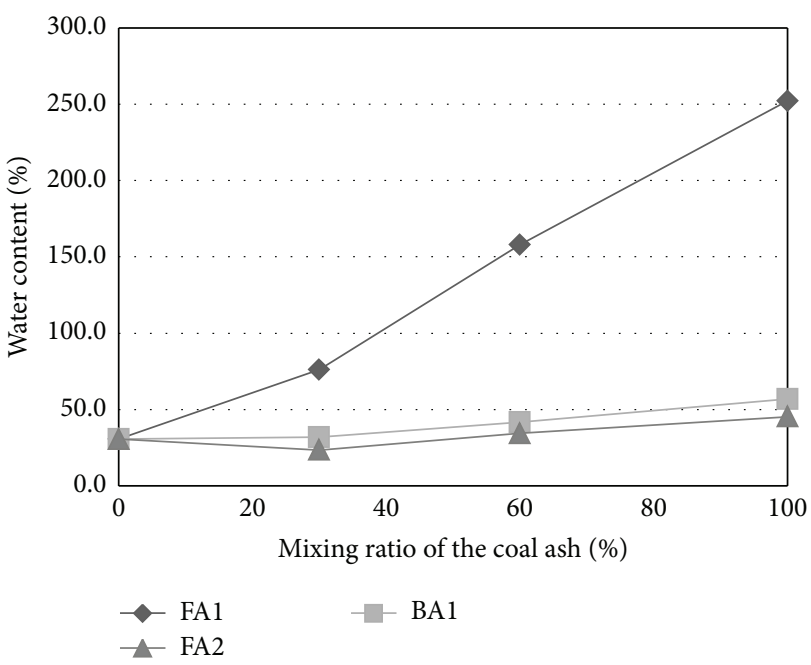

FIGURE 9: Water content of the simulated topsoil mixed with the coal ash at the mixing ratio of $0 \%, 30 \%, 60 \%$, and $100 \%$ in the artificial rainfall test.

owing to the decrease in surface stream water caused by improving the permeability in the simulated topsoil. The soil loss in the sample mixed with FA1 was, furthermore, less than that with BA1. This was possibly due to adhesion by water retained in microporous structures in FA1. When FA2 with low permeability due to a high content of silt was applied, soil erosion progressed with the increase in the ratio of surface stream water. This result indicated that soil composition which affected permeability in soils was important to predict soil erosion. Soil erosion could not be prevented by applying FA2 which consisted of more than $90 \%$ of clay and silt as shown in Figure 6. On the other hand, the risk of soil erosion could be reduced by FA1 and BA1 which consisted of more than $85 \%$ of sand at the mixing ratio of over $30 \%$. The mixing ratio, however, should be decided in consideration of the effects of soil composition on plant growth as well as on soil erosion in the case that coal ash is applied to postmine land.

\section{Conclusions}

In this study, the simulated topsoil mixed with coal ash was prepared to discuss the application of coal ash to postmine land for the purpose of prevention of soil erosion. The artificial rainfall test was performed with the samples in addition to the grain size analysis, the standard test for the Atterberg limits, falling head permeability test, and water retention test, aiming at understanding the change in risk of soil erosion by applying coal ash to topsoil. The main conclusions from the experiments are summarized as follows:

(i) The risk of soil erosion was significantly reduced by applying coal ash to topsoil which was considered industrial waste with a focus on physical characteristics of the ash.

(ii) The application of the coal ash which consisted of more than $90 \%$ of clay and silt to topsoil promoted 


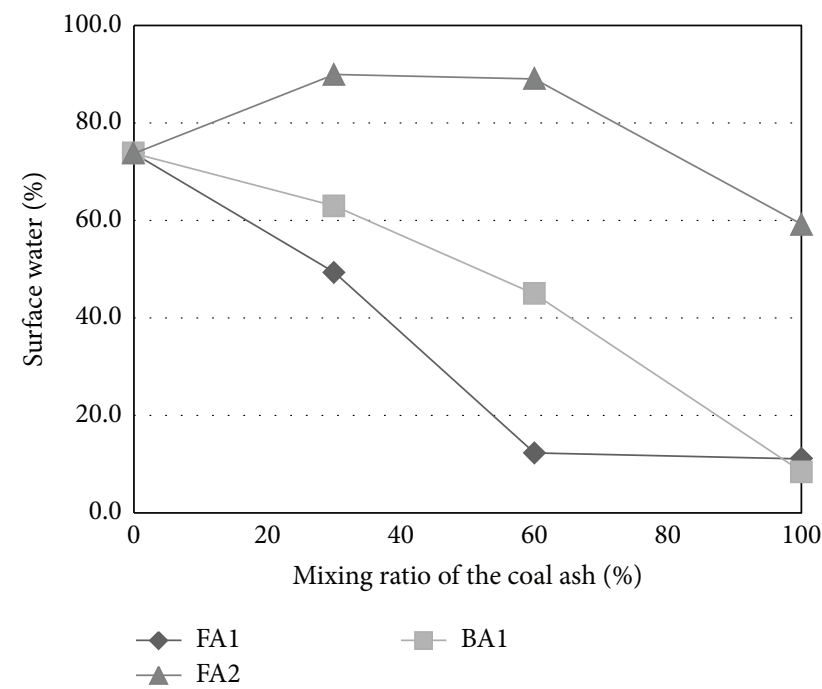

(a) Ratio of surface stream water

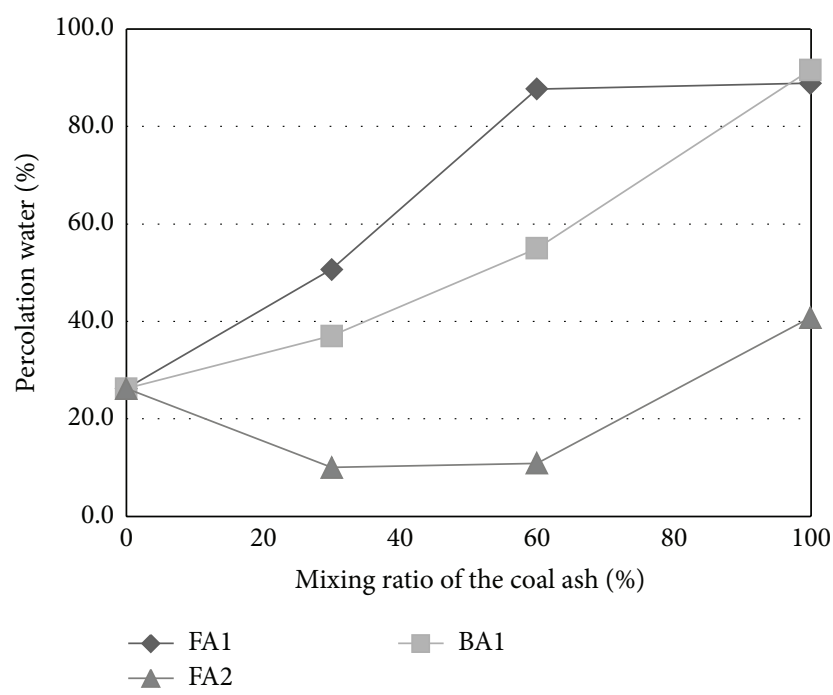

(b) Ratio of percolation water

FIGURE 10: Ratio of each type of water flow in the simulated topsoil mixed with the coal ash at the mixing ratio of $0 \%, 30 \%, 60 \%$, and $100 \%$ in the artificial rainfall test.

soil erosion. Meanwhile, soil erosion was prevented by mixing the coal ash which consisted of more than $85 \%$ of sand at the mixing ratio of over $30 \%$. However, the mixing ratio of coal ash to topsoil has to be decided in consideration of the effects of soil composition on plant growth as well as that on soil erosion.

(iii) Microporous structures in FA1 affected water retention capacity, leading to prevention of soil erosion. The coal ash of FAl with the structures showed high water retention in spite of low content of clay.

(iv) For the purpose of prevention of soil erosion by mixing coal ash in topsoil in postmine land, microporous structures in coal ash and soil composition which affect permeability and water retention capacity are useful to select coal ash and to decide the mixing ratio.

\section{Competing Interests}

The authors declare that there is no conflict of interests regarding the publication of this paper.

\section{Acknowledgments}

This research was supported by grants from the Advanced Graduate Program in Global Strategy for Green Asia, Kyushu University, and the Mitsui Matsushima Co., Ltd. The authors would like to express their gratitude and appreciation to the coal power plants for providing the coal ash samples and to the mine for kind assistance with field work. The authors also acknowledge the work of colleagues in the Laboratory of Rock Engineering and Mining Machinery, Kyushu University.

\section{References}

[1] International Energy Agency, Coal Information 2015-with 2014 Data, International Energy Agency, 2015.

[2] International Business Publications USA, Indonesia Energy Policy, Laws and Regulation Handbook, Volume 1: Strategic Information and Basic Laws, International Business Publications, Washington, DC, USA, 2015.

[3] H. Shimada, T. Sasaoka, K. Matsui et al., "Fundamental study of acid drainage control using flyash," in Proceedings of the 19th International Symposium on Mine Planning \& Equipment Selection, Fremantle, Australia, 2010.

[4] J. Skousen, J. E. Yang, J.-S. Lee, and P. Ziemkiewicz, "Review of fly ash as a soil amendment," Geosystem Engineering, vol. 16, no. 3, pp. 249-256, 2013.

[5] A. C. Chang, L. J. Lund, A. L. Page, and J. E. Warneke, "Physical properties of fly ash amended soils," Journal of Environmental Quality, vol. 6, no. 3, pp. 267-270, 1977.

[6] R. J. Haynes, "Reclamation and revegetation of fly ash disposal sites-challenges and research needs," Journal of Environmental Management, vol. 90, no. 1, pp. 43-53, 2009.

[7] S. Jala and D. Goyal, "Fly ash as a soil ameliorant for improving crop production-a review," Bioresource Technology, vol. 97, no. 9, pp. 1136-1146, 2006.

[8] K. C. Haering and W. L. Daniels, "Fly ash: characteristics and use in mineland reclamation, a literature review," Virginia Coal Energy Journal, vol. 3, pp. 33-46, 1991.

[9] J. H. Park, M. Edraki, D. Mulligan, and H. S. Jang, “The application of coal combustion by-products in mine site rehabilitation," Journal of Cleaner Production, vol. 84, no. 1, pp. 761-762, 2014.

[10] C. A. Ríos, C. D. Williams, and C. L. Roberts, "Removal of heavy metals from acid mine drainage (AMD) using coal fly ash, natural clinker and synthetic zeolites," Journal of Hazardous Materials, vol. 156, no. 1-3, pp. 23-35, 2008.

[11] K. C. Vories, "Placement of coal combustion by products at Surface Mining Control and Reclamation Act (SMCRA) mines: 
a short history of OSM technical efforts and responses to environmental concerns," in Proceedings of National Meeting of the American Society of Mining and Reclamation, Breckenridge, Colo, USA, 2005.

[12] G. J. Kusuma, H. Shimada, R. S. Gautama, K. Matsui, and C. H. Saputra, "An evaluation of fly ash-overburden rock mixtures for a cover layer to prevent acid mine drainage generation in overburden dump," in Proceedings of the ISRM International Symposium-8th Asian Rock Mechanics Symposium, Sapporo, Japan, 2014.

[13] A. Hamanaka, N. Inoue, H. Shimada, T. Sasaoka, and K. Matsui, "An experimental study for assessment of soil erosion at rehabilitation area in Indonesian coal mine," in Proceedings of the International Symposium on Land Reclamation and Ecological Restoration (LRER '14), pp. 171-175, Beijing, China, October 2014.

[14] M. J. M. Römkens, K. Helming, and S. N. Prasad, "Soil erosion under different rainfall intensities, surface roughness, and soil water regimes," Catena, vol. 46, no. 2-3, pp. 103-123, 2002.

[15] C. A. Igwe and N. Ejiofor, "Structural stability of exposed gully wall in Central Eastern Nigeria as affected by soil properties," International Agrophysics, vol. 19, no. 3, pp. 215-222, 2005.

[16] R. A. Obashi, "Vulnerability of soil erosion in Okitipupa area of Ondo state, Southwest Nigeria: a climatic problem," International Journal of Science and Technology, vol. 2, no. 4, pp. 326-335, 2013.

[17] K. Terzaghi, R. B. Peck, and G. Mesri, Soil Mechanics in Engineering Practice, John Wiley \& Sons, New York, NY, USA, 3rd edition, 1996.

[18] Y. Taniguchi, H. Komine, and S. Murakami, "Dominant influence of physico-chemical properties of soil to erosion characteristics of fine grain soil in river levee and bank," in Proceedings of the 46th Japan National Conference on Geotechnical Engineering, Kobe, Japan, 2011.

[19] ASTM, "Standard test methods for specific gravity of soil solids by water pycnometer," ASTM D854-14, ASTM International, 2014.

[20] ASTM, "Standard test method for particle-size analysis of soils (withdrawn 2016)," ASTM D422-63(2007)e2, ASTM International, 2007.

[21] ASTM, "Standard test methods for liquid limit, plastic limit, and plasticity index of soils," ASTM D4318-05, ASTM International, 2005.

[22] ASTM, "Standard test methods for measurement of hydraulic conductivity of saturated porous materials using a flexible wall permeameter," ASTM D5084-10, ASTM International, 2010.

[23] Japanese Geotechnical Society (JGS), "Test method for water retentivity of soils," Tech. Rep. JGS 0151-2009, Standards of Japanese Geotechnical Society for Laboratory Soil Testing Methods, 2009.

[24] K. Seki, "SWRC fit-a nonlinear fitting program with a water retention curve for soils having unimodal and bimodal pore structure," Hydrology and Earth System Sciences Discussions, vol. 4, no. 1, pp. 407-437, 2007.

[25] National Environment Agency, "Annual weather review 2011," http://www.nea.gov.sg/training-knowledge/publications/annual-weather-review-2011.

[26] A. Hamanaka, H. Shimada, T. Sasaoka, K. Matsui, I. Miyajima, and Y. Ichinose, "Assessment of soil erosion at the rehabilitation area in Indonesian coal mine," in Proceedings of the Spring Annual Symposium on the Mining and Materials Processing, Tokyo, Japan, 2013.
[27] A. Hamanaka, N. Inoue, H. Shimada, T. Sasaoka, K. Matsui, and I. Miyajima, "Study on backfilling of soil for revegetation at the rehabilitation area in Indonesian coal mine," in Proceedings of the 22nd Mine Planning and Equipment Selection, C. Drebenstedt and R. Singhal, Eds., Dresden, Germany, 2013.

[28] L. Dina, "Prospect of keprok orange in kutai timur regency," EPP, vol. 6, no. 1, pp. 36-43, 2009.

[29] A. A. Klyosov, Wood Plastic Composites, John Wiley \& Sons, Hoboken, NJ, USA, 2007.

[30] D. Havlíček, R. Přibil, and B. Kratochvíl, "Content of quartz and mullite in some selected power-plant fly ash in Czechoslovakia," Atmospheric Environment, vol. 23, no. 3, pp. 701-706, 1989.

[31] B. G. Kutchko and A. G. Kim, "Fly ash characterization by SEMEDS,” Fuel, vol. 85, no. 17-18, pp. 2537-2544, 2006.

[32] S. V. Vassilev, C. G. Vassileva, A. I. Karayigit, Y. Bulut, A. Alastuey, and X. Querol, "Phase-mineral and chemical composition of composite samples from feed coals, bottom ashes and fly ashes at the Soma power station, Turkey," International Journal of Coal Geology, vol. 61, no. 1-2, pp. 35-63, 2005. 

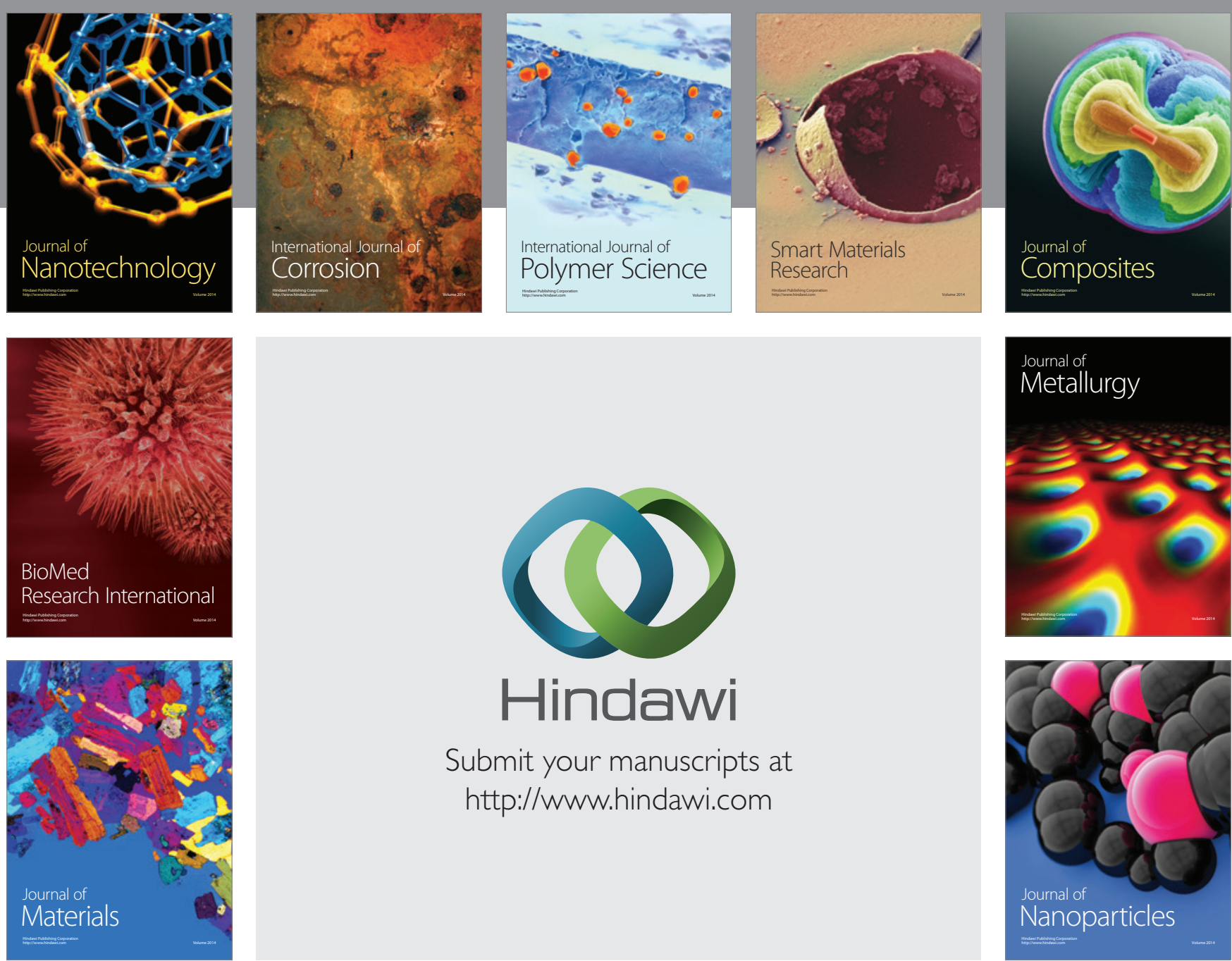

\section{Hindawi}

Submit your manuscripts at

http://www.hindawi.com

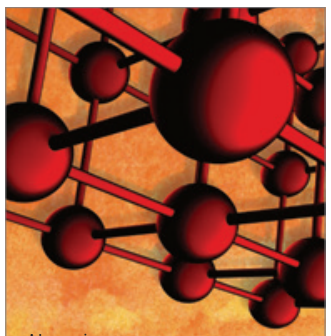

Materials Science and Engineering
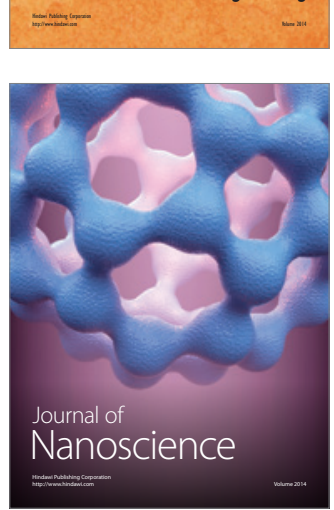
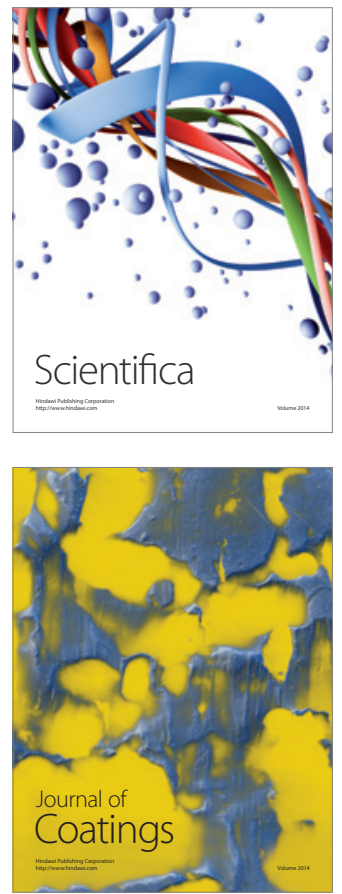
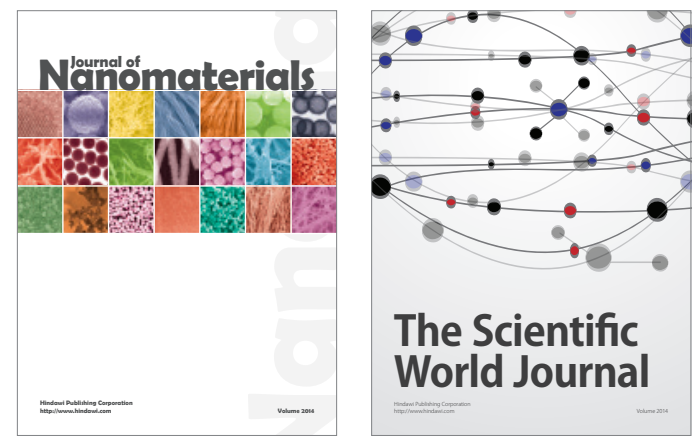

The Scientific World Journal
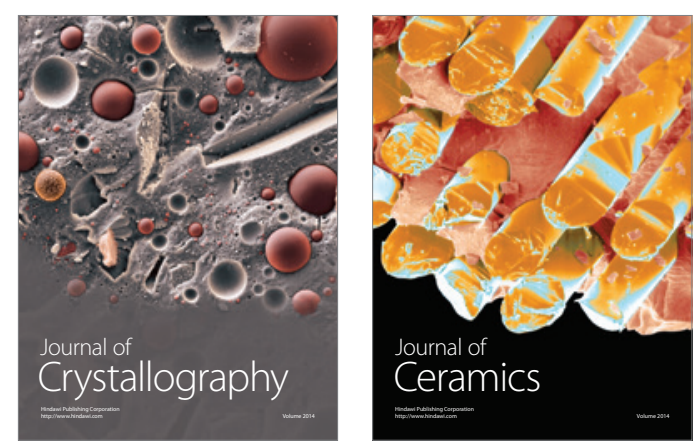
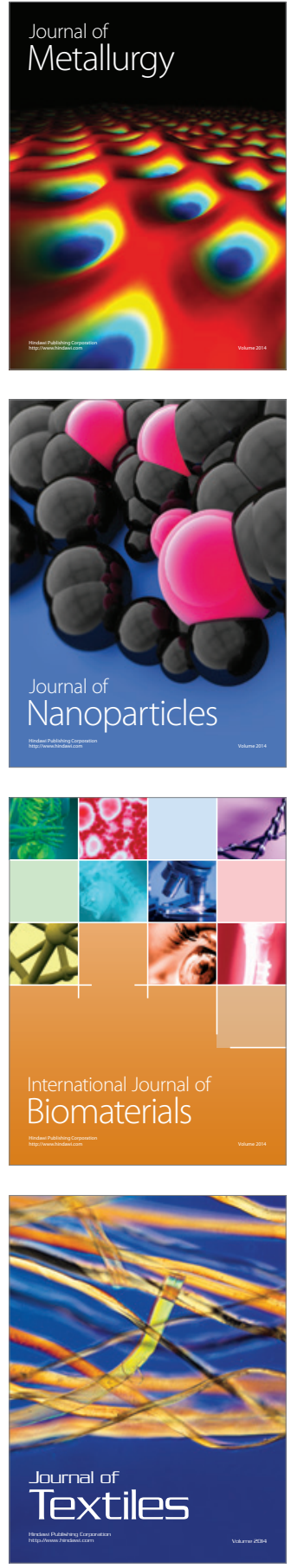